\title{
Who is energy poor? Evidence from the least developed regions in China
}

\author{
Lu Jiang ${ }^{1,2}, \mathrm{Lu} \mathrm{Yu}{ }^{3,4, \#}$, Bing Xue ${ }^{5}$, Xingpeng Chen ${ }^{1}$, Zhifu Mi ${ }^{2, *}$
}

1. College of Earth and Environmental Sciences, Lanzhou University, Lanzhou 730000, China;

2. The Bartlett School of Construction and Project Management, University College London, London, WC1E 7HB, UK;

3. Department of Land Management, Zhejiang University, Hangzhou, 310058, China;

4. German Development Institute-Deutsches Institut für Entwicklungspolitik (DIE), Bonn, 53113, Germany;

5. Institute for Advanced Sustainability Studies, Potsdam 14467, Germany

Abstract: Energy poverty has become one of the major challenges faced by the world's energy system. However, there is no consensus on the measure of energy poverty. Several approaches have been proposed, among which the energy poverty line has been defined as the minimum quantity of energy required for basic life, particularly for cooking and heating. This paper estimates the relationship between energy expenditure and household income and identifies the energy poverty line based on the threshold above which the energy share becomes insensitive to household income using household survey data from rural Qinghai, China. Considering the ongoing energy transition and the negative impacts of biomass energy consumption for the environment and health, the study sets a scenario in which all bioenergy consumption is replaced with electricity. The findings show that $57 \%$ of rural households in rural Qinghai are energy poor. The phase of energy poverty in terms of basic energy access has passed, so increasing the share of efficient modern energy in household energy consumption requires more attention. Considering the existence of a population that is not income poor but is energy poor, a conventional policy design that primarily targets income-poor households may be inappropriate in this case.

Keywords: Energy poverty, fuel poverty, energy access, energy transition, China

\footnotetext{
${ }^{*}$ Corresponding author. Email: z.mi@ucl.ac.uk (Z.Mi)

\# Lu Yu and Lu Jiang are the co-first authors.
} 


\section{Introduction}

Energy poverty, as one of three major challenges faced by the world's energy system, has severely restricted the sustainable development of human society (Sovacool et al., 2012). The 2030 Agenda for Sustainable Development highlighted energy poverty as a new level of political recognition in terms of the importance of energy to development, and it set the goal for everyone in the world to have "access to cheap, reliable and sustainable modern energy" by 2030 (UN, 2015). Energy access is not only important for achieving the target of SDG 7 but is also crucial for achieving many other goals, and there is a clear and important intersection between them. Today, 900 million people all over the world have no access to electricity (IEA, 2017). More than 2.1 billion people still rely on the burning of biomass energy for cooking, and $82 \%$ of these people are concentrated in Asia and Africa (IEA, 2017). They spend 1.4 hours each day collecting fuelwood, most of which is done by women (UN, 2015), which significantly reduces the time and opportunity for family members to engage in other production (SDG 8) and education training (SDG 4).

Solving the energy poverty challenge is now on the agenda of a number of countries, and there is a focus on the use of renewable energy sources, such as wind and solar energy, through the use of sustainable energy policies and financial-incentive policies that aim to expand access to electricity. For example, China has a goal of improving residential energy infrastructure by 2020 (the $13^{\text {th }}$ Five-Year Plan for Energy Development). It added that the upgrading of power grids and the replacement of energy should be coordinated to satisfy the electrical energy substitution in the heating field that is required by residents (NDRC, 2016). UK has released an annual Fuel Poverty Statistics Report since 2011, which made the eradication of energy poverty a legal obligation (DECC, 2018). The World Bank continues to produce research that addresses energy poverty by publishing the Global Tracking Framework for Sustainable Energy for All in 2017, and this publication proposed expanding the beneficiaries of modern energy services, improving energy efficiency and enriching applications of renewable energy (World Bank, 2017).

The study of energy poverty began in the 1970s and has drawn increasing attention from both academics and policy makers over the last two decades. The discussion of energy poverty mainly concerns 
two aspects: limited access to modern energy services and low affordability of energy access. The latter is also known as fuel poverty, as defined by John Hills: "when the cost of living energy paid to meet the basic living needs is higher than the social average, and the residual income is lower than the official economic poverty line" (Hills, 2011). This definition has been used to identify energy poverty in developed countries, such as the UK. The IEA has compiled various indicators to estimate the level of fuel poverty in developed countries, indicating that over $15 \%$ of the total population in developed countries suffers from fuel poverty. In developing countries, the focus of energy poverty is on the inaccessibility of modern energy, particularly a low access to electricity and clean modern cooking facilities. However, there is no internationally accepted measure of energy poverty in developing countries (Rademaekers et al., 2016). Energy poverty, particularly the inaccessibility of modern energy, has negative impacts on the environment and human health (González-Eguino, 2015). The direct burning of biomass energy for heating and cooking leads to indoor air pollution, threatening human health (World Bank, 2017). The indoor pollution caused by burning solid fuels leads to the premature death of approximately 4 million children and adults every year. The long-term exposure to high concentrations of indoor air pollution can easily cause acute lower respiratory infections, chronic obstructive pulmonary disease, lung cancer and other illnesses (Deep et al., 2018). Energy poverty also worsens the environment and exacerbates climate change. For example, fuelwood in Bangladesh satisfies half of the household energy demands in the country (Raupach et al., 2014). However, the use of fuelwood by farmers has caused damage to vegetation, which in turn has reduced the absorption capacity of carbon dioxide. The large amount of greenhouse gases released by solid fuels during combustion has exacerbated climate change (Abdullahi et al., 2014).

Energy poverty is a multidimensional phenomenon, and energy poverty in China is very complicated (Wang et al., 2015; Tang et al., 2014) due to the significant differences and inequalities in energy consumption caused by the differences in natural geography, socioeconomics, resource endowment and cultures across regions (Mi et al., 2018). In fact, a comprehensive assessment of the current status of energy poverty is the basis for the scientific formulation of policies to eliminate energy poverty and is also a prerequisite for the rational determination of relevant policy implementation targets. However, most of 
China's official statistics do not include micro-energy consumption information from families. The detailed micro-energy data are the basis for an energy poverty assessment. Therefore, household energy research in typical Chinese areas is of great importance to comprehensively and objectively judge China's energy poverty. Qinghai has distinguished characteristics in terms of its economic situation and energy consumption. In 2016, the per capita disposable income in rural areas was 9,450 yuan, which is only $70.4 \%$ of the average in China; thus, Qinghai ranked 27th among Chinese provinces. However, Qinghai was ranked fourth in terms of energy availability in China due to its abundant renewable energy resources (NDRC,2016). The development of solar and wind energy provides a reliable energy supply source (QSY, 2018). Moreover, due to its low population density $\left(2.61\right.$ people $\left./ \mathrm{km}^{2}\right)$, the energy self-sufficiency rate of Qinghai (over 100\%) is higher than the Chinese average (84.2\%) (QSY, 2018).

Through the development of the energy poverty line, this paper innovatively identifies an energy poverty line based on the sensitivities of the energy share to household income. This research provides a basis for differentiating between energy poor and income poor. The study uses Qinghai as an example to test the methods due to its current energy transition. This paper uses data collected through household surveys to investigate the energy consumption information of 440 households in 6 counties in Qinghai Province in the northeastern Qinghai-Tibetan Plateau.

\section{Measuring energy poverty}

Over the last two decades, with increasing attention being paid to issues related to energy poverty, diverse approaches have been developed to measure energy poverty (González-Eguino,2015). As a landmark index, The Energy Development Index (EDI), which was proposed by the International Energy Agency (IEA, 2017), has been used to monitor energy poverty across countries on a regular basis. It consists of 4 indicators, namely, per capita commercial energy consumption, per capita electricity consumption in the residential sector, share of modern fuels in total energy use in the residential sector (\%), and percentage of population access to electricity (\%) (IEA, 2017). The index offers a practical tool for cross-country comparisons and enables the monitoring of country development in the energy sector. While the EDI captures the energy development towards modern fuel systems, the Multidimensional Energy Poverty Index 
(MEPI), provided by the UNDP, directly illustrates both a headcount ratio of those identified as energy poor and the intensity of deprivation among the energy poor. However, both indexes focus primarily on the accessibility of residents to modern energy while failing to adequately consider other dimensions, such as biomass resources, which remain an important component of energy consumption in developing countries; furthermore, these indexes do not reveal the energy poverty situation at the local level.

Instead of such indexes that are built upon several variables and sophisticated calculations, another type of approach that has been used to estimate energy poverty is based on a single indicator that defines a minimum energy requirement level. Those who do not reach the minimum level are considered to be energy poor. For example, for many countries, especially those in Europe, the value of $10 \%$ has been defined as a cutoff point of the maximum share of energy expenditure of the household's income, which means that those who spend less than $10 \%$ of their income on energy are energy non-poor (IEA, 2018). However, energy consumption is often location-specific and can be affected by energy prices, traditions and cultures, and a single threshold rarely satisfies all influential factors (Barnes et al., 2011). Therefore, it is important to identify the poverty line based on case-specific conditions. Barnes et al. provides an innovative method to define the tipping point of energy consumption, below which energy consumption increases slowly as income rises; above that point, energy consumption and household income are positively correlated until the next tipping point is reached, above which energy consumption will not rise proportionately with the increase in income but rather remains still. The first point defines the energy poverty line at which energy is used to sustain basic life needs; the second point is a theoretical saturation point, which seems far from being reached in the case of Bangladesh. They used regression to estimate the sensitivity of household energy consumption to per capital income after controlling for several household and village variables. Ten income deciles were included in the regression, and the average energy consumption in the last income decile in which the income and energy demand start to have a significant relationship is defined as the poverty line. This method creatively solves the problem of context diversity, as it considers local specificities and country differences and is therefore able to derive a poverty line that better fits with specific 
cases. This fits well with the context of Bangladesh, where energy poverty is fairly pervasive and access to electricity is limited.

However, in our case, a recently released energy report ranked Qinghai the least energy poor and among the top five in terms of both household energy affordability and energy efficiency and energy management completeness (Wang et al., 2015). Electricity in Qinghai is accessible to more than $95 \%$ of rural households, implying a high accessibility to efficient modern energy. Considering the unique conditions of Qinghai, we extend Barnes et al.'s method by considering the affordability of modern energy rather than focusing on the minimum energy requirement of life. Therefore, we examine the relationship between energy share and household income. More detailed information will be provided in the fifth section.

\section{Research background}

\subsection{Research site}

The Qinghai-Tibet Plateau is known as the third pole of the Earth. The region is unique, as it has abundant natural resources but a fragile ecological environment and is home to rich ethnic cultures but is economically impoverished (Ping et al., 2011). Qinghai province is located in the northeastern QinghaiTibetan Plateau. Most parts of the territory have an elevation higher than 3,000 m, with the eastern part being relatively low altitude and the southern part being high altitude. The annual average temperature of the province is $2.1^{\circ} \mathrm{C}$, with the southern part being extremely cold. Its special geographic location, as well as its unique landforms and climatic conditions, have formed three types of geographic regions from east to west: pastoral, agro-pastoral and agricultural, providing the livelihood for a total rural population of 3.44 million. In 2017, the per capita disposable income of the rural population was 9,460 yuan, which is only $70.4 \%$ of the national level. There was a large impoverished population in the region.

Qinghai is an ideal case to study in terms of the renewable energy transition. It has the fourth largest wind field in China, and the wind energy reserves account for $9.4 \%$ of China's wind energy reserves. The area ranks second in China in terms of solar radiation (5800-7400 MJ/m2), following Tibet. Three major rivers of China (i.e., the Yellow, Yangtze and Lancang) originate in Qinghai, providing good hydrothermal conditions. In 2018, Qinghai was officially announced a national clean energy demonstration province. The 
goal of achieving $51 \%$ of the energy production and $41 \%$ of the energy consumption in the province using renewables by 2020 was set. In 2019, Qinghai succeeded in carrying out a 15-day trial of supplying all energy for its 6 million residents from renewable sources, following a nine-day trial in the previous year. This has marked a new record in the country's efforts to push the low-carbon development path.

However, the energy transition in rural Qinghai is more challenging. In 2017, the energy consumption of rural residents was 1.041 million tons of standard coal, accounting for $40 \%$ of the total energy consumption of urban and rural residents. Currently, rural energy consumption remains highly dependent on traditional energy. The collection of animal manure and crop residue for households energy consumption has to certain extent influenced the sustainability of the ecosystems. As a scarcely populated area, the construction costs of public energy facilities in rural Qinghai are relatively high. In addition, Qinghai is the key target area for China's policies related to grazing bans and transferring farmland to forest programs, which has impacts on the access to traditional energy sources among the rural population.

\subsection{Data}

The data used for this study were collected from a household survey conducted in rural Qinghai in 2018. Following a cluster sampling strategy, 50 villages (taking into consideration location, agricultural types and ethnicities) from 6 counties (Figure 1) were selected, and 15 households were interviewed in each village. Due to the extremely low population density, the sample size was adjusted in some villages. In total, 440 valid questionnaires were collected based on face-to-face interviews, with an average interview time of 1 hour. Among those interviewed, 207 were from the farming area, 143 were from the agro-pastoral area and 90 were from the pastoral area.

The survey generated a data set containing detailed information relevant to residential energy consumption, including household information, such as household income, household size, education of the household head, assets, labor force and agricultural production, and we recorded the details of household energy consumption, such as the breakdown of energy sources, the consumption and expenditure of each energy source, how households obtain these resources, and the difficulties in obtaining each source. Existing research mostly focuses on the energy consumption of households for cooking and heating (Pereira 
et al., 2011). However, in recent years, with the improvement of infrastructure and the geographic extension of social activities and networks, the energy used for transportation in rural households has increased rapidly, which can affect the availability of energy, the price of energy, and the time required for collecting biomass energy (Sovacool et al., 2012). Therefore, we also include household transportation energy use in the study as an important supplement to the energy discourse. Such energy includes mainly the gasoline and diesel consumed for vehicles. In recent years, electric bicycles have become increasingly used in rural China. However, among our sampled households, the possession of electric bicycles remains limited, and it is technically difficult to separate the exact amount of electricity used for charging bicycles out of the total electricity consumption. Therefore, in this study, all electricity consumption falls into the general energy use for life, instead of into the category of transportation energy consumption.

(Figure 1 here )

\subsection{Energy consumption in the research site}

The survey results show the strong reliance of local households on biomass energy in rural Qinghai (Table 1); biomass energy (i.e., crop residue, fuelwood, and animal dung) accounts for $41.4 \%$ of the total household energy consumption. Biomass energy dominates household energy use for many reasons. First, in rural areas, biomass resources are abundant and are with low costs. The crop residue and fuelwood are mainly from household agricultural production; animal dungs are collected from households that own animals. Only in very limited cases will pastoralists pay for animal dungs, as in two counties of the sampling where local households buy animal dungs when there is a shortage from the local animal husbandry. The price is fairly low, i.e., $300 \mathrm{Rmb}$ for 1 ton of animal dungs. Second, although it is increasingly acknowledged that the direct burning of biomass energy for cooking has negative impacts on the indoor environment and health of household members, specifically for women (WHO, 2013; Pereira et al.,2011), this is not well known by local farmers. Therefore, although it costs time to collect biomass sources, they remain the key component of household energy. Notably, in recent decades, due to the implementation of 
grazing ban policies ${ }^{1}$ and transferring farmland to forest programs, the supply of biomass sources has declined (Chen et al., 2017), which might re-shape the structure of energy consumption at the household level in the long term and might become a driver that encourages a shift in household energy consumption away from biomass energy.

The utilization of modern energy, including electricity, coal and gas for cooking and heating as well as gasoline and diesel for transportation, in the study area is $60.6 \%$. Electricity is used for kitchen work and daily household activities (in recent years, it has also been used for heating electric blankets and charging electric motorcycles, though these uses remain limited). Coal is mainly used for cooking and heating, and gas is used exclusively for kitchen work. The average regional power access rate in Qinghai is 97.9\% (QSY, 2018). The agricultural and pastoral areas in the research area had achieved a full power supply. Only very few households in pastoral areas lack access to electricity; these households rely on panels purchased with government subsidies to generate electricity.

Coal is one of the most important commercial energy sources for the research region, with more than $86 \%$ of households using coal for household energy consumption. In recent years, national policies have indirectly promoted the use of coal by rural families. For example, due to the implementation of the policy of returning grazing land to grassland, the amount of livestock farming in pastoral areas has decreased. Currently, the amount of available livestock manure is insufficient to meet daily needs. Families living close to coal mining areas gradually replace traditional energy with coal because it is convenient for them to obtain coal. However, a high level of household air pollution is associated with coal. The current clean energy utilization rates of solar and biogas in the areas surveyed are low, i.e., less than $3 \%$ and $12 \%$, respectively. However, the survey showed that residents can use only low-power appliances, such as electric lights, due to the battery capacity and voltage limits of solar energy. Furthermore, $2.5 \%$ of interviewed households use biogas, accounting for $0.77 \%$ of the total household energy consumption. Moreover, it has

\footnotetext{
${ }^{1}$ Grazing ban policy was implemented since early 2000s in major pastoral provinces of China. It prohibited or restricted livestock grazing. More information can be read in Yu and Farrell, 2013; Ho, 2016
} 
been found that the biogas digesters were currently not being used due to technical problems, such as poor sealing and odor spillover, which also hinders its further promotion.

In the past 10 years, with the spatial expansion of economic activities, the travel frequency of residents has increased, and transportation energy expenditures have also grown each year. The results showed that $80.1 \%$ of the families surveyed had gasoline consumption. The diesel utilization rate $(25 \%)$ was significantly lower than that of gasoline $(75.68 \%)$. The main reasons are as follows: first, the herders have gradually replaced traditional horse-riding and grazing with motorcycles, and as a consequence, the number of modern vehicles as well as the use of gasoline and diesel has increased. Second, affected by factors such as government subsidies for housing purchases and access to high-quality education, herders tend to buy houses in cities or towns, which are mainly used by the elderly and children. The herders (mainly the young generation) remain in the pastoral areas to care for grazing livestock. The traffic energy consumption has increased due to the herders' commute between pastoral areas and towns.

Qinghai is rich in solar energy due to its special geological position and climate. In most areas, the direct solar radiation is above $1800 \mathrm{kWh} /\left(\mathrm{m}^{2} \bullet\right.$ year $)$, and in some areas, it is $2000 \mathrm{kWh} /\left(\mathrm{m}^{2} \bullet\right.$ year $)$. Thus, the area is suitable for building solar thermal power stations (QPS, 2018). In 2016, the newly installed capacity of photovoltaic power generation was 1.19 million $\mathrm{kWh}$, and the cumulative installed capacity was 682 $\mathrm{kWh}$, ranking second in China. China became the world's leading market for solar energy production in 2013. However, research shows that clean energy use is very limited in rural areas (Geall, 2018).

( Table 1 here )

\section{Estimating energy poverty in Qinghai}

Following Barnes et al. (2011), this study examines the relationship between income and energy consumption at the household level through regressions. As argued in the previous section, considering the context of Qinghai, access to energy is not the main focus of the province; rather, the focus is on the transition towards efficient and clean energy. If we consider Qinghai's energy consumption based on the EDI's four indicators, we will see that almost all the population has access to electricity. Access to 
electricity has been commonly considered a key feature differentiating energy poor and energy non-poor populations. Therefore, it is inappropriate to evaluate energy poverty based on energy consumption in the context of Qinghai. We examine the relationship between energy share and household income, aiming to find the tipping point at which the household energy share becomes insignificantly related to household income.

We use regressions (1) to estimate the sensitivity of the household energy share to its household income. Learning from previous studies, income is a key factor influencing household energy consumption and structure. An increase in income will first cause an increase in household energy consumption and then cause a shift away from the consumption of biomass energy towards the consumption of modern commodity energy (Démurger and Fournier, 2011; Chen et al., 2006), as high-income families can achieve energy transition more easily than can low-income families. Thus, low-income families rely on traditional fuelwood as the main source of energy (Leach, 1992; Hosier and Kipondya, 1993).

In regression (1), $x_{i}$ refers to a column vector of control variables for household $i$, including household size, labor force, education level and age of the head of the household, coal prices and agricultural land assets. Farmland and grassland assets are used as proxies for household wealth. Two dummy variables are also included to indicate the household access to clean energy (i.e., biogas and solar energy), as well as an indicator of coal price. The variable of interest here is a column vector of $D$, that is, the household income deciles. The dependent variable $y_{i}$ refers to the total energy share (including transportation) of household income in model 1 , while we use the percentage of energy expenditure excluding transportation in household income as the dependent variable in model 2. $\varepsilon_{i}$ is an error term.

$y_{i}=x_{i}^{\prime} \beta+D_{i}^{\prime} \gamma+\varepsilon_{i}$

The results show that for the energy share without transportation energy use (model 2), starting from the $5^{\text {th }}$ income decile, the household income no longer has significant impacts on the energy share, which means that the households have reached enough commercial energy to meet the family's needs, and the increase in income will not proportionately enhance the use of these energies. Therefore, the average energy share in the $4^{\text {th }}$ income decile, which is $6.88 \%$, can be considered as the threshold dividing those who are 
energy poor and those who are energy non-poor. For the total energy share (when transportation is considered), the threshold lies in the $5^{\text {th }}$ income decile, which is $13.31 \%$ (Table 2).

\section{(Table 2 here )}

As shown in figure 2, approximately $40 \%$ of the population falls under the poverty line, which means that they are energy poor. There are slight differences in different calculations (e.g., 42.1\% when transportation energy use is considered compared with $41.9 \%$ when transportation is excluded). As expected, the percentage of those who are energy poor decreases when the household income increases.

(Figure 2 here )

\section{Who is energy poor in Qinghai}

\section{- Based on the current scenario}

We found that those who have been defined as energy poor in this study are actually consuming more energy (3363 kgce) than those who are energy non-poor (2649 kgce). This confirms that measuring energy poverty by focusing on the minimum energy requirement for life (Barnes et al., 2011) does not fit with the context of Qinghai. Pachauri and Jiang (2008) found that in China, although less-wealthy families consume more energy in total amount, their consumption relies more on biomass energy and coal, which are considered as inefficient (Niu et al., 2019; Pachauri and Jiang, 2008). A close examination of the types of energy consumed among our sample population shows consistent results. We find that energy-poor households were more likely to consume more energy and spend a higher percentage of income on energy than non-poor households (Figure.3). However, the energy poor households consumed a significantly higher percentage of solid energy (e.g., biomass energy and coal) in household energy consumption (59.4\% of total energy consumption) than those identified as energy non-poor (71.5\%). Therefore, we may conclude that among our sample population, residential total energy consumption is not the key indicator for identifying energy poor and energy non-poor; in other words, access to energy is not a key problem, but the consumption of efficient and clean modern energy is. This is consistent with the observation (Table 1) 
that biomass energy use still dominates households' energy consumption, indicating that in general, the household energy transition in rural Qinghai remains incomplete.

With regard to the use of clean energy, there are no significant differences in the annual consumption of biogas between the energy poor and energy non-poor $(\mathrm{p}=0.7607)$, but there are significant differences in solar energy consumption between the two groups ( $\mathrm{p}=0.0121$ ), although the consumption is generally very limited in both groups (575 kgce for energy poor vs 229 kgce for energy non-poor).

(Figure 3 here )

\section{- Based on a scenario replacing solid energy consumption with electricity}

To address the problem, those who are defined as energy non-poor based on our calculation are highly dependent on biomass energy, the direct use of which is widely accepted as inefficient and unhealthy for family members, especially women. We established a scenario A in which all biomass energy consumption was replaced with electricity. This scenario is technically possible, considering that in Qinghai, the access rate to electricity is approximately $98 \%$. To do this, we first calculated the total bioenergy consumption of each household with the unit of kgce. Then, we assigned related electricity to each household to replace the bioenergy consumption. Third, we calculated the extra expenditure of the electricity assigned and added it to the current energy expenditure. We then achieved a database of the energy share in the household income in the scenario $\mathrm{A}$ in which we eliminated bioenergy and replaced it with electricity. We compared the revised energy share in household income with the energy poverty line that was defined earlier (i.e., $6.88 \%$ excluding transportation energy expenditure, $13.31 \%$ including transportation energy expenditure) to determine household energy-poverty status in the new scenario.

Following the same methods, we further established scenario B on the basis of scenario A, in which all coal consumption was also replaced with electricity. Therefore, in scenario B, all the consumption of inefficient solid energy was replaced with more efficient alternative-electricity.

As shown in Figure 4, the overall energy poverty rate increased from $42.1 \%$ to $52.8 \%$ when transportation was considered and from $41.9 \%$ to $57.2 \%$ when transportation was not considered in scenario 
A; and increased to $50.90 \%$ when transportation was considered and to $55 \%$ when transportation was not considered in scenario B. We suggest that these energy poverty rates are more pragmatic, although they may sound pessimistic. Considering the inefficiency of using solid energy, the negative impacts of the use of solid energy on human health and particularly the direct use of biomass, and the negative environmental effects this energy may involve, the transition away from using solid energy is aligned with the governmental agenda.

(Figure 4 here )

If we replace bioenergy consumption with clean energy techniques (e.g., biomass energy or solar energy), the pressure of increasing energy poverty may be eased. However, considering the technical difficulties (Zhang et al.,2018), the region is still a long way from replacing the direct use of bioenergy with clean energy.

\section{- Energy poor vs income poor}

Based on the energy poverty lines drawn above and the income poverty line set by the Chinese Government, which is the per capital annual net income of $3256 \mathrm{Rmb}$, our sample can be divided into four categories: (I) the population that is both income and energy poor, (II) the population that is not income poor but energy poor, (III) the population that is both income and energy non-poor, and (IV) the population that is income poor and energy non-poor. Figure 5 shows the different energy poor distributions in the current scenario and in the scenario A.

In general, we can see that income poor households are mostly also energy poor, though there exists a very limited share in the group that is income poor and energy non-poor $(1.81 \%$ in the baseline scenario and $0.68 \%$ in the new scenario). The major change between the two scenarios is found in the group of energy-poor households that are income non-poor, which account for $24.77 \%$ in the baseline scenario and outnumber the share of households that are energy poor and income poor (17.5\%) and is expected to surge to $41.14 \%$ in scenario A, when all bioenergy use is replaced by electricity. This implies that the conventional policy design that primarily targets income-poor households may be not sufficient in rural 
Qinghai. Considering the current transition towards clean and efficient energy, the population of income non-poor but energy poor households requires special attention, in particular those that would be newly added in the new scenario.

We examine the characteristics of energy-poor households in the baseline scenario and find that in addition to the likelihood of their reliance on solid energy for household energy use, as outlined above, those identified as energy poor are generally likely to be older and poorer, have less land and be less educated (Table 3). Being energy poor, implying consuming a higher percentage of solid energy in this case, poses challenges to the health of household members. Globally, the consumption of solid energy causes 4 million deaths every year due to respiratory and cardiovascular diseases (WHO, 2013). In the Tibetan area of China, the use of biomass energy for cooking has intensified the indoor air pollution, threatening the health of family members (Ping et al., 2011). This may result in low production efficiency and extra costs for medical care, thus leading to a poverty trap (Frankenberg et al., 2005). In addition, the collection of biomass energy requires sufficient working hours, which could otherwise be devoted to study (children) and production (Pereira et al., 2011). Considering that in our case, the energy poor are likely to be the elderly and the poor, they are vulnerable to the above highlighted health impacts and negative economic effects.

A closer look at the income of those identified as energy poor and income non-poor, whom we argue to be worthy of attention but currently neglected by policy makers, shows that this group mainly constitutes those whose income level is in the third and fourth income deciles. In contrast, in scenario A, those newly added to the group of energy poor and income non-poor are mainly those in higher income deciles (4th to 7th decile) (Figure 6).

(Table 3 here )

(Figures $5 \& 6$ here )

\section{Conclusions and policy implications}


The measurement of energy poverty is the basis for energy poverty research and the basis for energy poverty alleviation policy decisions. However, due to the great difference in physical and climate conditions, as well as the diversity of the social-economic context across regions, it is difficult to evaluate energy poverty using a single energy poverty line (Barnes et al., 2011), based either on the minimal energy requirement or on the share of energy expenditure on household income. Building upon Barnes et al. (2011)'s approach to study the energy poverty line, based on the case of Qinghai Province, we provide another solution to define the energy poverty line based on household data, which considers the significant diversities of the context. By acknowledging the unique energy consumption features of Qinghai Province, illustrated by its wide access rate to electricity and high dependence on bioenergy, we use the sensitivity of the energy share to household income as an indicator to identify the energy poverty line, above which the energy share is no longer significantly positively related to household income. To address the problem that the energy non-poor who are identified are highly dependent on the use of bioenergy, we set a scenario to replace all bioenergy consumption with electricity, compiling the new data set to compare to the previously defined energy poverty line. We concluded that more than half of the rural households are considered energy poor in the study area of Qinghai.

Under the influence of human activities, such as urbanization and industrialization, as well as climate change and regional ecological governance, carrying out energy poverty measurements in Qinghai Province as a case area is conducive to filling the gap between the energy poverty status and policy formulation and provides a scientific basis for energy transitions in the ecologically fragile Qinghai-Tibet Plateau. Our research shows that as one of the most advanced provinces in terms of energy access (Wang et al., 2015), households in rural Qinghai are free from the basic problem of accessing energy. The challenge is how to steer the transition towards efficient and clean energy while maintaining household living standards, as our results show that more than $40 \%$ of household energy consumption is sustained from the use of bioenergy, and approximately half of the rural households still use bioenergy. If we consider the free access to and affordability of efficient modern energy, the energy poverty rate is still a major challenge in Qinghai. 
Policy should be designed to encourage the energy poor to continue transferring to efficient and clean energy while reducing energy costs by providing more choices and support for clean energy (e.g., solar energy and biogas). Affordable and efficient modern energy and reliable clean energy are needed to relieve the energy poverty situation, which is also in line with China's low-carbon development strategy (Guan and Delman, 2017). For example, Qinghai Province's ample clean energy could be used by deploying distributed solar photovoltaic systems to help families obtain solar equipment and pay for the cost of electricity they generate. For isolated areas that do not have access to solar photovoltaic equipment, the advantages of solar power, including generation, flexible installation, environmental friendliness, and affordability, can be fully utilized to reduce the cost of electricity and energy. It is also found that biogas has a significant substitution effect on the direct burning of animal dungs, crop residues, and fuelwood Therefore, there is great potential for promoting clean energy in rural areas (Jiang et al., 2019). In terms of construction scale, the characteristics of the environmental climate must be fully considered, and centralized large-scale biogas plants should gradually be promoted. To push biogas construction plans forward, the budget should be increased, and the maintenance services should be strengthened.

The acquisition and consumption of transportation energy should also be included in the focus of energy poverty (Sovacool, 2012). We find that due to the gradual popularization of modern vehicles such as household cars, agricultural vehicles and battery-powered vehicles, transportation energy has become the main growth point of household energy consumption and shows a further growth trend. Therefore, in future energy policy, it is necessary to increase the focus on the transportation department.

Acknowledgements: This research was funded by National Key R\&D Program of China (2018YFC0704702) and the Key Lab for Environmental Computation and Sustainability of Liaoning Province Project (20180110); We appreciate the support from the German BMBF Kopernikus Project for the Energy Transition-Thematic Field No. 4 "System Integration and Networks for the Energy Supply" (ENavi), and the support from China Scholarship Council (201806180102). 


\section{References}

[1] Sovacool, B.K., Cooper, C., Bazilian, M., Johnson, K., Zoppo, D., Clarke, S., Eidsness, J., Crafton, M., Velumail, T., Raza, H.A., 2012. What moves and works: Broadening the consideration of energy poverty. Energy Policy 42, 715-719. https://doi.org/10.1016/j.enpol.2011.12.007

[2] UN (The United Nations). 2015. Transforming our World: The 2030 Agenda for Sustainable Development. Available online: https://www.un.org/sustainabledevelopment/development-agenda/.

[3] IEA (International Energy Agency). 2017.Real-World Policy Packages for Sustainable Energy Transitions. Available online: https://www.iea.org/publications/insights/insightpublications/Realworldpolicypackagesforsustainableenergytransitions.pdf

[4] NDRC (National Development Reform Commission of China). 2016. 13th Five-Year Plan for Energy Development. Available online: http://www.ndrc.gov.cn/zcfb/zcfbghwb/201701/W020170117350627940556.pdf.

[5] World Bank. 2017. Global Tracking Framework for Sustainable Energy for All in 2017. Available online: http://www.worldbank.org/en/topic/energy/publication/global-tracking-framework-2017

[6] Hills, J. 2011. Fuel poverty: The problem and its measurement. St. Louis: Federal Reserve Bank of St Louis. Retrieved from https://search.proquest.com/docview/1698355797?accountid=14511

[7] DECC (Department of Energy \& Climate Change). 2018. Annual report on fuel poverty statistics. Available online: https://assets.publishing.service.gov.uk/government/uploads/system/uploads/attachment data/file/719106/Fuel Poverty Statistics Report 2018.pdf

[8] Rademaekers, K., Yearwood, J., Ferreira, A., Pye, S., Hamilton, I., Agnolucci, P., ... \& Anisimova, N. 2016. Selecting indicators to measure energy poverty. Trinomics: Rotterdam, The Netherlands.

[9] González-Eguino, M., 2015. Energy poverty: An overview. Renew. Sustain. Energy Rev. 47, 377-385. https://doi.org/10.1016/j.rser.2015.03.01

[10] Chakraborty, D., Mondal, N.K., 2018. Hypertensive and toxicological health risk among women exposed to biomass smoke: A rural Indian scenario. Ecotoxicol. Environ. Saf. 161, 706-714. https://doi.org/10.1016/j.ecoenv.2018.06.024

[11] Raupach, M.R., Davis, S.J., Peters, G.P., Andrew, R.M., Canadell, J.G., Ciais, P., Friedlingstein, P., Jotzo, F., van Vuuren, D.P., Le Quéré, C., 2014. Sharing a quota on cumulative carbon emissions. Nat. Clim. Change 4, 873-879. https://doi.org/10.1038/nclimate2384

[12] Abdullahi, K.L., Delgado-Saborit, J.M., Harrison, R.M., 2013. Emissions and indoor concentrations of particulate matter and its specific chemical components from cooking: A review. Atmos. Environ. 71, 260-294. https://doi.org/10.1016/j.atmosenv.2013.01.061

[13] Wang, K., Wang, Y.-X., Li, K., Wei, Y.-M., 2015. Energy poverty in China: An index based comprehensive evaluation. Renew. Sustain. Energy Rev. 47, 308-323. https://doi.org/10.1016/j.rser.2015.03.041

[14] Tang, X., Liao, H., 2014. Energy poverty and solid fuels use in rural China: Analysis based on national population census. Energy Sustain. Dev. 23, 122-129. https://doi.org/10.1016/j.esd.2014.08.006

[15] Mi, Z., Zheng, J., Meng, J., Shan, Y., Zheng, H., Ou, J., Guan, D., Wei, Y.-M., 2018. China's Energy Consumption in the New Normal. Earths Future 6, 1007-1016. https://doi.org/10.1029/2018EF000840

[16] QPS, 2018, Qinghai Province Statistical Yearbook. Available online: http://www.qhtjj.gov.cn/nj/2018/indexch.htm

[17] IEA (International Energy Agency). 2017. Methodology for Energy Access Analysis. Available online: https://www.iea.org/media/publications/weo/EnergyAccessOutlook2017Definingandmodellingenergyaccess.pdf.

[18] EEA (European Environment Agency). 2018. Energy Consumption in Households. Available online: https://www.eea.europa.eu/airs/2018/resourceefficiency-and-low-carbon-economy/household-energy-consumption.

[19] Barnes, D.F., Khandker, S.R., Samad, H.A., 2011. Energy poverty in rural Bangladesh. Energy Policy 39, 894-904. https://doi.org/10.1016/i.enpol.2010.11.014. 
[20] Ping, X., Jiang, Z., Li, C., 2011. Status and future perspectives of energy consumption and its ecological impacts in the Qinghai-Tibet region. Renew. Sustain. Energy Rev. 15, 514-523. https://doi.org/10.1016/j.rser.2010.07.037

[21] Giannini Pereira, M., Vasconcelos Freitas, M.A., da Silva, N.F., 2011. The challenge of energy poverty: Brazilian case study. Energy Policy 39, 167175. https://doi.org/10.1016/j.enpol.2010.09.025

[22] WHO (World Health Organization). The world health report 2013: Research for Universal Health Coverage. Available online: https://apps.who.int/iris/bitstream/handle/10665/85761/9789240690837 eng.pdf;jsessionid=D88E686DB7FF1E321C3DA89450B82E9A?sequence $=2$

[23] Yu, L., Farrell, K.N., 2013. Individualized Pastureland Use: Responses of Herders to Institutional Arrangements in Pastoral China. Hum. Ecol. 41, 759-771. https://doi.org/10.1007/s10745-013-9580-1

[24] Ho, P., 2016. Empty institutions, non-credibility and pastoralism: China's grazing ban, mining and ethnicity. J. Peasant Stud. 43, 1145-1176. https://doi.org/10.1080/03066150.2016.1239617

[25] Chen, X., Lupi, F., Liu, J., 2017. Accounting for ecosystem services in compensating for the costs of effective conservation in protected areas. Biol. Conserv. 215, 233-240. https://doi.org/10.1016/j.biocon.2017.09.013

[26] Geall, S., Shen, W., Gongbuzeren, 2018. Solar energy for poverty alleviation in China: State ambitions, bureaucratic interests, and local realities. Energy Res. Soc. Sci. 41, 238-248. https://doi.org/10.1016/j.erss.2018.04.035

[27] Démurger, S., Fournier, M., 2011. Poverty and firewood consumption: A case study of rural households in northern China. China Econ. Rev. 22, 512-523. https://doi.org/10.1016/j.chieco.2010.09.009

[28] Chen, L., Heerink, N., van den Berg, M., 2006. Energy consumption in rural China: A household model for three villages in Jiangxi Province. Ecol. Econ. 58, 407-420. https://doi.org/10.1016/j.ecolecon.2005.07.018

[29] Leach, G.1992. The energy transitions. Energy policy, 20(2), 116-123. https://doi.org/10.1016/0301-4215(92)90105-B

[30] Hosier, R.H., Kipondya, W., 1993. Urban household energy use in Tanzania. Energy Policy 21, 454-473. https://doi.org/10.1016/0301$\underline{4215(93) 90035-E}$

[31] Zhang, W., Wang, C., Zhang, L., Xu, Y., Cui, Y., Lu, Z., Streets, D.G., 2018. Evaluation of the performance of distributed and centralized biomass technologies in rural China. Renew. Energy 125, 445-455. https://doi.org/10.1016/j.renene.2018.02.109

[32] Niu, S., Li, Z., Qiu, X., Dai, R., Wang, X., Qiang, W., \& Hong, Z. 2019. Measurement of effective energy consumption in China's rural household sector and policy implication. Energy policy, 128, 553-564.https://doi.org/10.1016/j.enpol.2019.01.016

[33] Pachauri, S., \& Jiang, L. 2008. The household energy transition in India and China. Energy policy, 36(11), 4022-4035. https://doi.org/10.1016/j.enpol.2008.06.016

[34] Frankenberg, E., McKee, D., \& Thomas, D. 2005. Health consequences of forest fires in Indonesia. Demography, 42(1), 109129. https://doi.org/10.1353/dem.2005.0004

[35] Guan, T., \& Delman, J. 2017. Energy policy design and China's local climate governance: energy efficiency and renewable energy policies in Hangzhou. Journal of Chinese Governance, 2(1), 68-90. https://doi.org/10.1007/978-981-13-2799-5 32

[36] Jiang, L.,Yu, L., Xue, B., Chen, X. 2019. Regional Characteristics of Household Energy Consumption Structure in Qinghai Province. Economic Geography, 39(08):146-152+176. (In Chinese)

[37] Sovacool, B.K., 2012. Deploying Off-Grid Technology to Eradicate Energy Poverty. Science 338, 47-48. https://doi.org/10.1126/science.1222307 


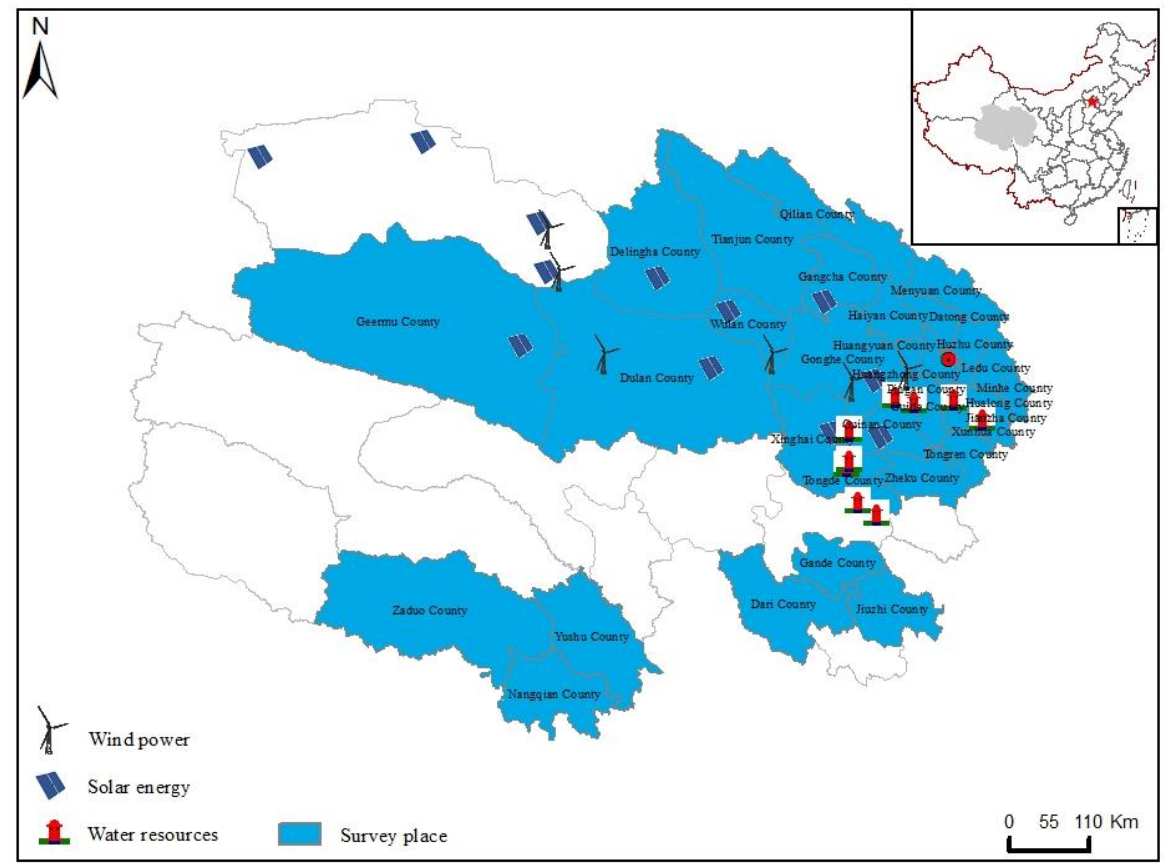

Figure 1. Survey location: map of Qinghai Province with surveyed countries in blue

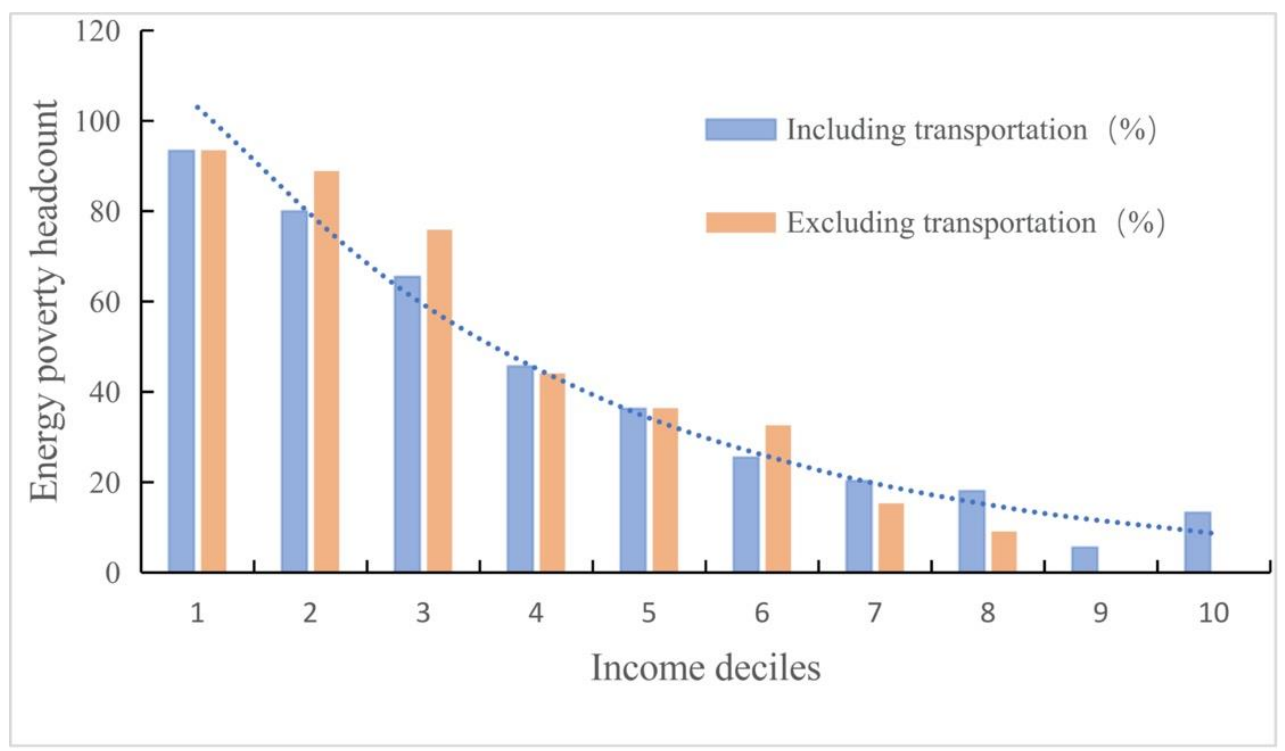

Figure 2. Energy poverty headcount when transportation energy consumption is and is not considered 

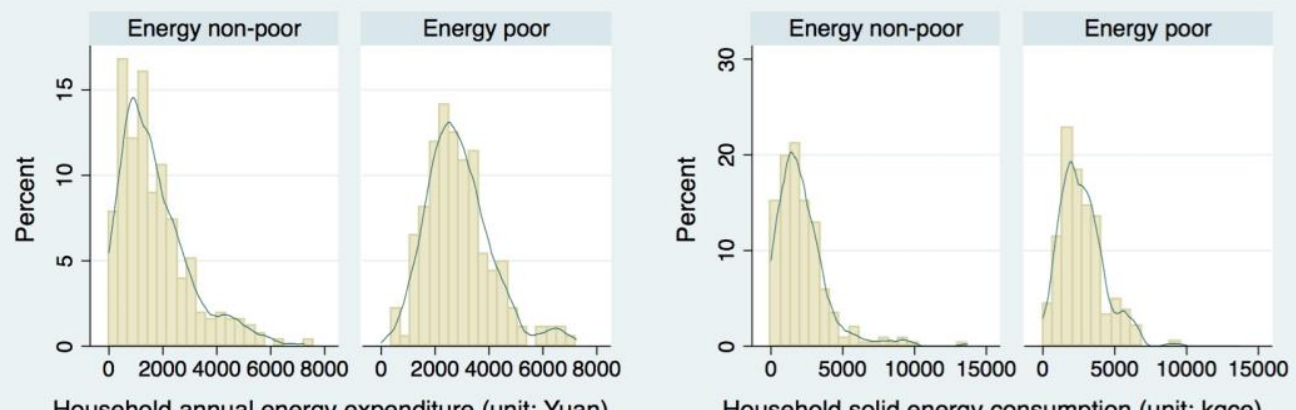

Household annual energy expenditure (unit: Yuan) Household solid energy consumption (unit: kgce)
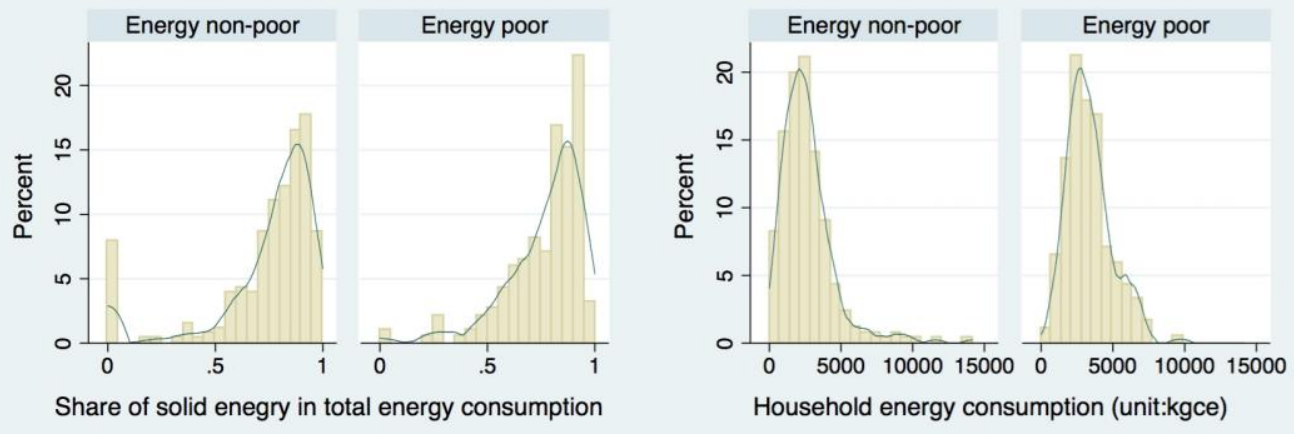

Figure 3. Energy consumption and expenditure (excluding energy used for transportation) between the energy poor and energy non-poor 

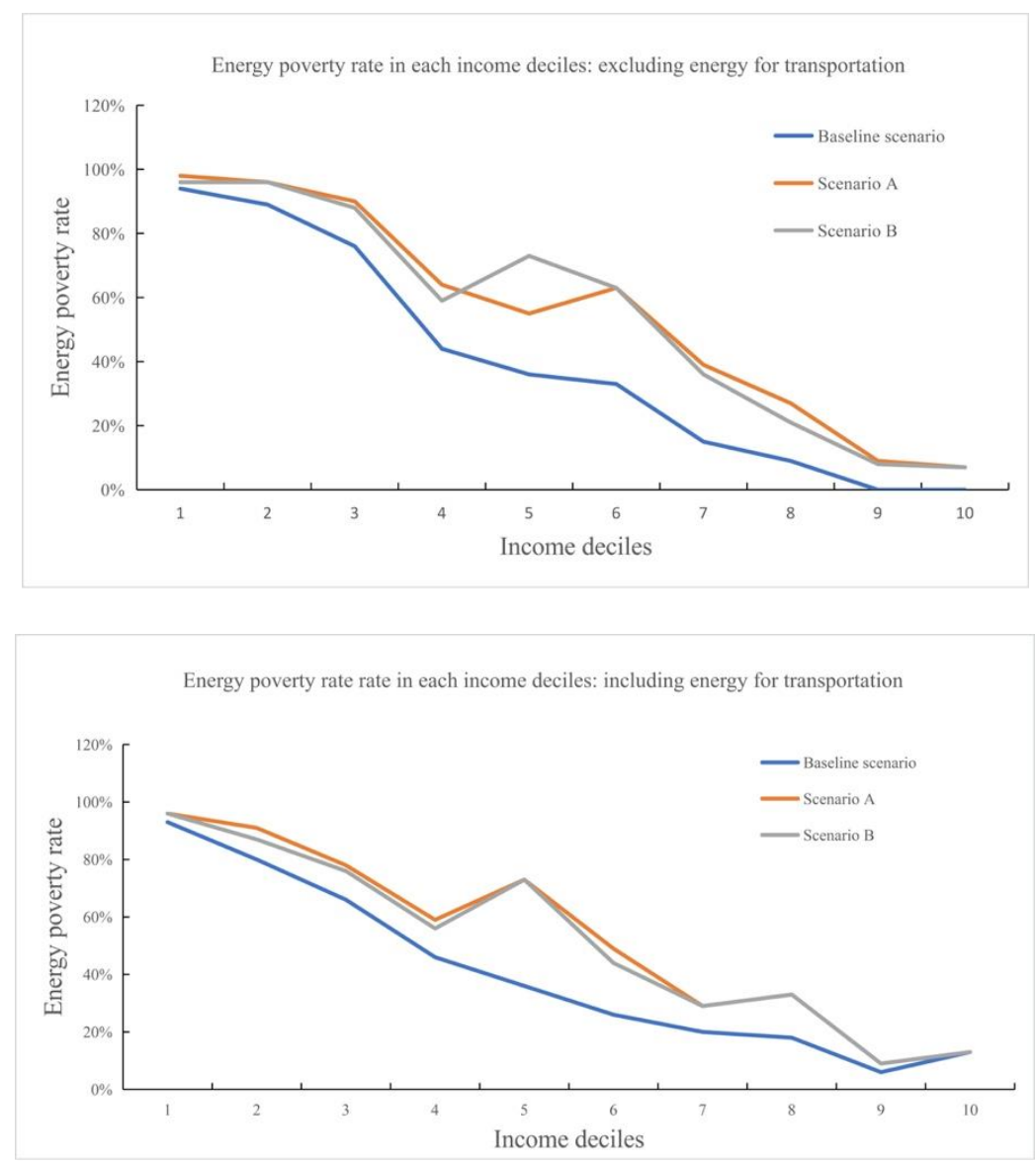

Figure 4. Household energy poverty rate in different scenarios

Income poor and energy poor in the basedline scenario

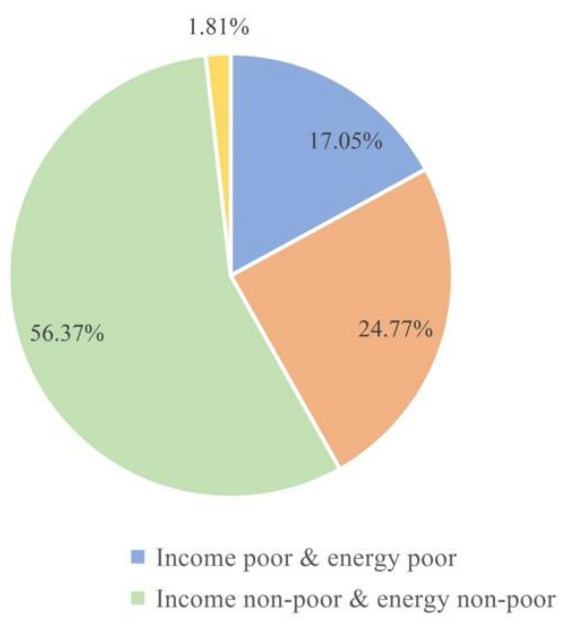

Income poor and energy poor in the scenario A

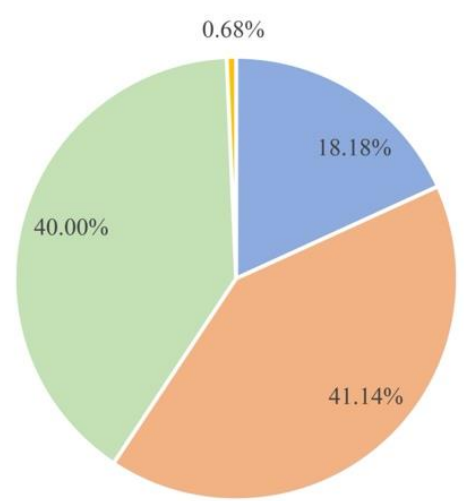

Income non-poor \& energy poor

Income poor \& energy non-poor

Figure 5. Income poor and energy poor in different scenarios 


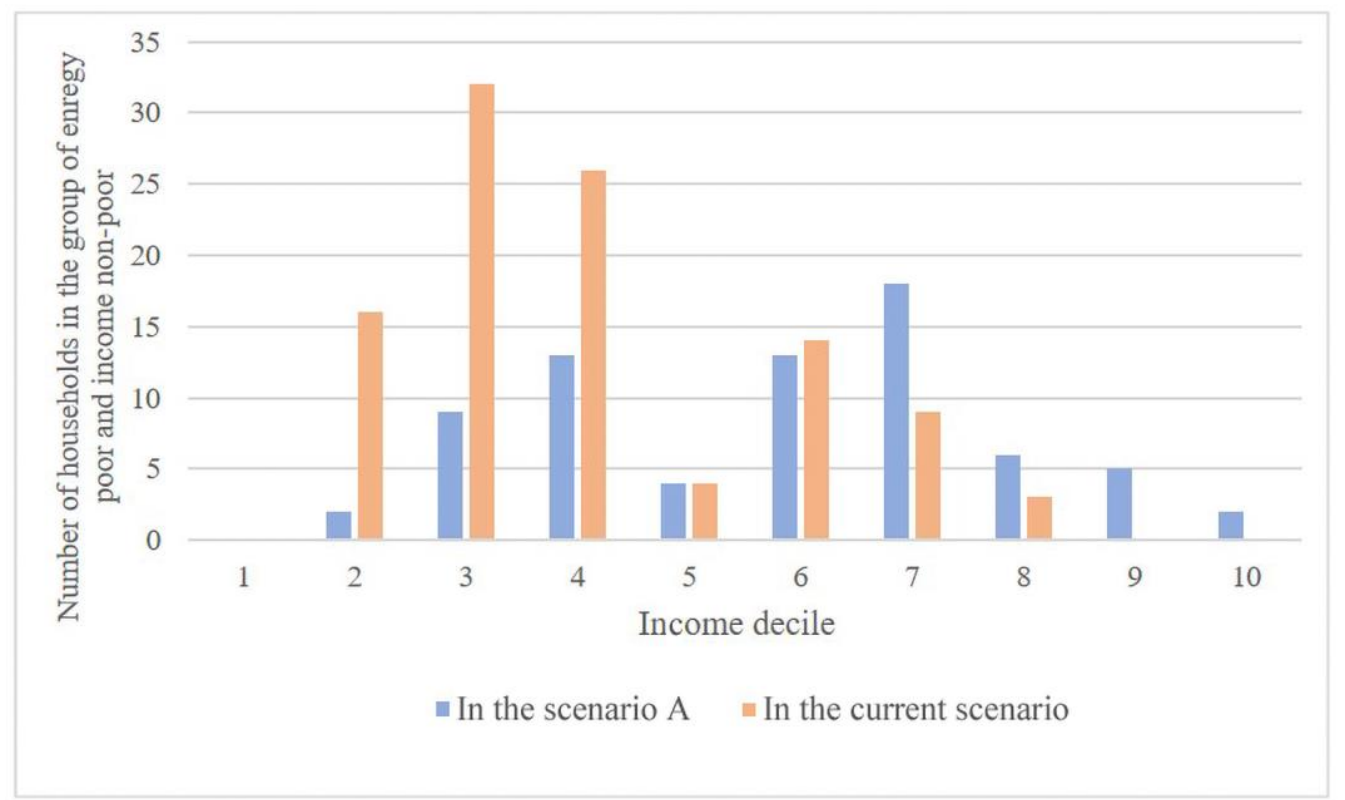

Figure 6. Distribution of the population that falls into the category of being energy poor and income nonpoor in different scenarios

Table 1. Household energy use in rural Qinghai $(\mathrm{N}=440)$

\begin{tabular}{|c|c|c|c|c|c|c|c|c|c|c|c|}
\hline Energy source & $\begin{array}{l}\text { Crop } \\
\text { residue }\end{array}$ & Fuelwood & $\begin{array}{c}\text { Animal } \\
\text { dung }\end{array}$ & Coal & $\begin{array}{c}\text { Grid } \\
\text { electricity }\end{array}$ & Gasoline & Diesel & Kerosene & Biogas & Solar & \\
\hline $\begin{array}{l}\text { Share of total energy } \\
(\%)\end{array}$ & 4.95 & 16.66 & 19.08 & 34.90 & 4.09 & 12.55 & 1.01 & 4.17 & 0.77 & 0.37 & 100.00 \\
\hline $\begin{array}{l}\text { Households using } \\
\text { the source }(\%)\end{array}$ & 39.09 & 52.50 & 54.54 & 84.54 & 97.95 & 75.68 & 25.00 & 20.00 & 2.50 & 11.82 & \\
\hline $\begin{array}{l}\text { Share of energy } \\
\text { expenditure }(\%)\end{array}$ & 0.00 & 0.00 & 5.41 & 63.32 & 21.26 & 0.00 & 0.00 & 10.01 & 0.00 & 0.00 & 100.00 \\
\hline
\end{tabular}

Source: own survey data 
Table 2. Estimates of household energy share

\begin{tabular}{|c|c|c|c|c|}
\hline \multirow[t]{3}{*}{ Explanatory variables } & \multirow{2}{*}{\multicolumn{2}{|c|}{$\begin{array}{c}\text { Model 1 } \\
\begin{array}{c}\text { Energy share (including } \\
\text { transportation) }\end{array}\end{array}$}} & \multicolumn{2}{|c|}{ Model 2} \\
\hline & & & \multicolumn{2}{|c|}{$\begin{array}{l}\text { Energy share (excluding } \\
\text { transportation) }\end{array}$} \\
\hline & Coefficient & t-statistic & Coefficient & t-statistic \\
\hline Household income & -0.0023 & -1.81 & -0.0015 & -1.83 \\
\hline Household size & -0.0037 & -0.78 & -0.0014 & -0.3 \\
\hline Labor force in a household & 0.0004 & 0.06 & -0.0016 & -0.29 \\
\hline $\begin{array}{l}\text { Years of education of the head } \\
\text { of household }\end{array}$ & 0.0009 & 0.74 & -0.0004 & -0.39 \\
\hline Age of the head of household & 0.0009 & 1.79 & 0.0008 & 1.6 \\
\hline Household grassland (ha) & 0 & 0.14 & -0.0001 & -0.9 \\
\hline Household farmland (ha) & 0.0071 & 0.45 & 0.0136 & 1.34 \\
\hline $\begin{array}{l}\text { Number of electric appliances } \\
\text { in the household }\end{array}$ & 0.0089 & 4.68 & 0.0055 & 3.45 \\
\hline Log price of coal (Rmb/ton) & 0.036 & 0.69 & 0.1030 & 3.35 \\
\hline $\begin{array}{l}\text { Having solar energy } \\
(1=\text { yes; } 0=\text { no })\end{array}$ & -0.018 & -1.61 & 0.0032 & 0.55 \\
\hline $\begin{array}{l}\text { Having biogas pool/equipment } \\
(1=\text { yes; } 0=\text { no })\end{array}$ & 0.0139 & 0.7 & 0.0061 & 0.33 \\
\hline \multicolumn{5}{|c|}{ Household income decile (excluding 10th decile category) } \\
\hline 1st & 0.2497 & 7.15 & 0.2227 & 7.81 \\
\hline 2nd & 0.1623 & 4.79 & 0.1346 & 5.58 \\
\hline 3rd & 0.0774 & 3.03 & 0.0647 & 5.08 \\
\hline 4th & 0.0511 & 2.08 & 0.0266 & 1.8 \\
\hline 5th & 0.0503 & 1.99 & 0.0082 & 0.61 \\
\hline 6th & 0.0217 & 1.01 & 0.0090 & 0.72 \\
\hline 7th & 0.0217 & 0.94 & 0.0093 & 0.77 \\
\hline 8th & 0.0233 & 1.13 & 0.0074 & 0.74 \\
\hline 9th & 0.0015 & 0.11 & 0.0055 & 0.72 \\
\hline Cons & -0.2271 & -0.66 & -0.7064 & -3.42 \\
\hline Observation & \multicolumn{2}{|c|}{439} & \multicolumn{2}{|c|}{439} \\
\hline Adjusted $\mathbf{R}^{2}$ & \multicolumn{2}{|c|}{0.4748} & \multicolumn{2}{|c|}{0.5815} \\
\hline
\end{tabular}

Note: 1 . The explanatory variables also include dummy variables for the seven regions (cities);

2. The t-statistic results are based on robust standard errors clustered at the county level. 
Table 3. Summary of household characteristics between the energy poor and energy non-poor

\begin{tabular}{lccl}
\hline Variables & Energy poor & Energy non-poor & Difference \\
\hline Age of household head & 52,58 & 48,08 & $4,49 * * *$ \\
& $(0,89)$ & $(0,75)$ & \\
Education of household head & 5,48 & 6,37 & $0,89 * *$ \\
Household income & $(0,27)$ & $(0,23)$ & \\
& 2,09 & 6,6 & $4,51 * * *$ \\
Farmland possession & $(0,10)$ & $(0,29)$ & \\
& 7,27 & 5,47 & $1,80 * * *$ \\
Household size & $(0,47)$ & $(0,37)$ & \\
& 4,34 & 4,09 & $0,24 * *$ \\
Percentage of solid energy & $(0,09)$ & $(0,07)$ & \\
consumption in total energy & 0,71 & 0,59 & $0,12 * * *$ \\
\hline
\end{tabular}

Note: $* \mathrm{p}<0.10, * * \mathrm{p}<0.05, * * * \mathrm{p}<0.01$. 